Research Article

\title{
Climate Warming in Response to Emission Reductions Consistent with the Paris Agreement
}

\author{
Fang Wang $\mathbb{D},{ }^{1}$ Katarzyna B. Tokarska, ${ }^{2}$ Jintao Zhang, ${ }^{3}$ Quansheng Ge $\left(\mathbb{D},{ }^{3}\right.$ \\ Zhixin Hao (iD, ${ }^{3}$ Xuezhen Zhang, ${ }^{3}$ and Maowei $\mathrm{Wu}$ (iD) ${ }^{3}$ \\ ${ }^{1}$ Department of Climate and Environment Change, Key Laboratory of Land Surface Pattern and Simulation, \\ Institute of Geographic Sciences and Natural Resources Research, Chinese Academy of Sciences, \\ 11A, Datun Road, Chaoyang District, Beijing 100101, China \\ ${ }^{2}$ School of Earth and Ocean Sciences, University of Victoria, 3800 Finnerty Road, Victoria, BC, Canada, V8W 3V6 \\ ${ }^{3}$ Department of Climate and Environment Change, Institute of Geographic Sciences and Natural Resources Research, \\ Chinese Academy of Sciences, Beijing, China
}

Correspondence should be addressed to Fang Wang; wangf@igsnrr.ac.cn

Received 1 September 2017; Revised 12 March 2018; Accepted 29 March 2018; Published 8 May 2018

Academic Editor: Annalisa Cherchi

Copyright (c) 2018 Fang Wang et al. This is an open access article distributed under the Creative Commons Attribution License, which permits unrestricted use, distribution, and reproduction in any medium, provided the original work is properly cited.

To limit global warming to well below $2^{\circ} \mathrm{C}$ in accord with the Paris Agreement, countries throughout the world have submitted their Intended Nationally Determined Contributions (INDCs) outlining their greenhouse gas (GHG) mitigation actions in the next few decades. However, it remains unclear what the resulting climate change is in response to the proposed INDCs and subsequent emission reductions. In this study, the global and regional warming under the updated INDC scenarios was estimated from a range of comprehensive Earth system models (CMIP5) and a simpler carbon-climate model (MAGICC), based on the relationship of climate response to cumulative emissions. The global GHG emissions under the updated INDC pledges are estimated to reach 14.2 15.0 GtC/year in 2030, resulting in a global mean temperature increase of $1.29 \sim 1.55^{\circ} \mathrm{C}\left(\mathrm{median}\right.$ of $\left.1.41^{\circ} \mathrm{C}\right)$ above the preindustrial level. By extending the INDC scenarios to 2100, global GHG emissions are estimated to be around 6.4 9.0 $\mathrm{GtC} /$ year in 2100 , resulting in a global mean temperature increase by $2.67 \sim 3.74^{\circ} \mathrm{C}$ (median of $3.17^{\circ} \mathrm{C}$ ). The Arctic warming is projected to be most profound, exceeding the global average by a factor of three by the end of this century. Thus, climate warming under INDC scenarios is projected to greatly exceed the long-term Paris Agreement goal of stabilizing the global mean temperature at to a low level of $1.5-2.0^{\circ} \mathrm{C}$ above the pre-industrial. Our study suggests that the INDC emission commitments need to be adjusted and strengthened to bridge this warming gap.

\section{Introduction}

To limit global mean warming to well below $2^{\circ} \mathrm{C}$, in accordance with the Paris Agreement [1], 190 countries submitted their Intended Nationally Determined Contributions (INDCs), which outline the intended post-2020 emission plans of each country [2]. INDCs became the first target of greenhouse gas (GHG) mitigation reached through a bottom-up approach by nationally intended efforts, so it is easier to monitor a level of commitment than before through a top-down system. However, the impacts of these emission-reduction efforts on climate warming are poorly understood and their adequacy to meet the long-term goal of stabilizing the global mean temperature to $1.5^{\circ} \mathrm{C}$ or $2^{\circ} \mathrm{C}$ above the preindustrial level is still unknown.

To simulate climate response under INDC scenarios, running a full suite of comprehensive Earth system models (ESMs), such as the CMIP5 models (Coupled Model Intercomparison Project), is unrealistic due to the high computational cost, while running only one certain model is not representative of climate response of the Earth system due to potential model biases. Recent studies have shown a near linear relationship between cumulative carbon emissions and temperature change [3-10]; thereby providing a way to 
evaluate climate response under INDC scenarios without the need of running additional simulations by comprehensive Earth system models.

In the Fifth Assessment Report (AR5) of the Intergovernmental Panel on Climate Change (IPCC) [11], future climate change was projected under a set of Representative Concentration Pathway (RCP) scenarios, using a model ensemble of comprehensive Earth system models (CMIP5) [12] and a reduced-complexity carbon-cycle and climate model (Model for the Assessment of Greenhouse Gas Induced Climate Change (MAGICC)) $[13,14]$. The ratio of temperature increase to cumulative carbon emissions, also referred to as the transient climate response to cumulative carbon emissions (TCRE), is relatively constant over time and is independent of the $\mathrm{CO}_{2}$ emissions pathway $[4,15,16]$. Expert judgements $[4,5,7,10]$ based on multiple lines of evidence estimate TCRE to be likely between $0.8^{\circ} \mathrm{C}$ and $2.5^{\circ} \mathrm{C}$ per $1000 \mathrm{GtC}$ ( 5 to $95 \%$ ), of cumulative $\mathrm{CO}_{2}$ emissions. Most of the above studies presented results only for $\mathrm{CO}_{2}$ emissions, without considering the effects of non- $\mathrm{CO}_{2}$ forcing. When non- $\mathrm{CO}_{2}$ GHG forcing is considered, the additional net warming from non- $\mathrm{CO}_{2}$ forcings contributes to lower levels of emissions allowed to reach the given temperature target [16-18].

Therefore, estimates of the climate response to cumulative carbon emissions provide a useful benchmark for assessing the climate response under different emission scenarios. In this study, we make use of the available data of climate responses to cumulative emissions based on CMIP5 and MAGICC simulations, to estimate the global mean warming in response to the INDC scenarios. This study is structured as follows: Section 2 describes the methods and data sources, Section 3.1 presents the conditional and unconditional INDC committed emissions, Section 3.2 examines climate responses to cumulative emissions in CMIP5 and MAGICC models and presents an estimate of warming under INDC emission scenarios, while Section 4 provides the conclusions and further discussion.

\section{Data and Methods}

2.1. INDC Data. The INDC dataset is continuously updated, and includes 192 countries (165 INDCs) that submitted their pledges up to 2017 (July). Most countries have reported their composite targets, such as emission targets, energy targets, forest targets, and adaptation targets [2]. The emission targets reported by countries vary from absolute emission target (e.g., reducing emissions by a given amount of $\mathrm{GtC} /$ year) to emission target relative to the base year level (e.g., reducing emissions back to 2010 or 2000 levels), or emission-reduction target relative to the baseline emission scenario (e.g., reducing emissions compared with the business-as-usual scenario (BAU, 2030 levels)). The base years of emission data of each country were obtained from the UNFCCC national inventories [19]. The baseline scenario data of each country were calculated according to the predicted emissions from the Stockholm Environment Institute [20]. The reported emission targets of each country were extracted and, subsequently, total cumulative emissions were calculated (see Section 2.2). The
165 INDCs cover 192 countries, which together account for more than $99 \%$ of global GHG emissions. In addition, three countries (Libya, Nicaragua, and Syria) still had not submitted INDC reports at the time of this analysis. The INDC emission targets consist of both the unconditional targets (voluntary emission reductions, irrespective of the actions of other countries) and conditional targets (more aggressive mitigation actions if certain conditions are met regarding the provision of finance or technological assistance from developed countries). Supplementary Table S1 shows the INDCs of the 165 countries (up to July 2017) analyzed in this study.

\subsection{Calculating Cumulative Global INDC Emissions.} Global cumulative INDC emissions were estimated by summing national INDC emissions for each year. National INDC commitments provide the emission level of the pre2030 period (Figure 1). For the post-2030 period, annual emission pathways were obtained by linear interpolation based on the expected level of development. The global emissions are assumed to peak in 2030 and then decline steadily (Figure 2). We assume that the continued action of national emission reduction was adopted in the scenario over the 21st century, and the relatively constant decarbonisation rates were followed for the period after 2030 .

2.3. Temperature Response to INDC Emissions. The temperature response to cumulative INDC emissions was estimated based on a well-established framework of climate response to cumulative carbon emissions $[3,4,6,8-10,16]$.

Cumulative carbon emissions and temperature responses from RCP experiments were used to construct a function of climate responses to cumulative emissions referred to as TCRE $_{\text {all }}$ (Figure 3):

$$
\mathrm{TCRE}_{\mathrm{all}}=\frac{\Delta T}{\Delta I}
$$

where $\mathrm{TCRE}_{\mathrm{all}}$ represents the climate response for all GHGs, both for $\mathrm{CO}_{2}$ effect and for non- $\mathrm{CO}_{2}$ GHG effect. $\Delta I$ represents the cumulative anthropogenic $\mathrm{GHG}$ emissions above the current level in 2012, including $\mathrm{CO}_{2}$ and other non- $\mathrm{CO}_{2}$ GHG emissions. All non- $\mathrm{CO}_{2}$ emissions were converted into a unified unit of $\mathrm{CO}_{2}$ equivalent emissions, according to the global warming potential of each gas [21]. $\Delta T$ is the corresponding change of global temperature, subject to decadal smoothing. These data were obtained from the RCP simulation experiments for CMIP5 and MAGICC models.

The warming above the current level $\left(\Delta T_{\text {INDC }}\right)$ under the INDC scenarios was estimated by the following equation:

$$
\Delta T_{\mathrm{INDC}}=\mathrm{TCRE}_{\mathrm{all}} \times \Delta I_{\mathrm{INDC}},
$$

where $\Delta I_{\text {INDC }}$ represents cumulative emissions (from year 2012) under the INDC scenarios, which was calculated by summing national INDC emissions for each year.

Then, the warming level above the preindustrial level was estimated based on the sum of the INDC warming above the current level $\left(\Delta T_{\text {INDC }}\right)$ and the current warming above the preindustrial level. The current warming in 2012 was estimated to be about $0.85 \pm 0.14^{\circ} \mathrm{C}[22]$. 
(\%)

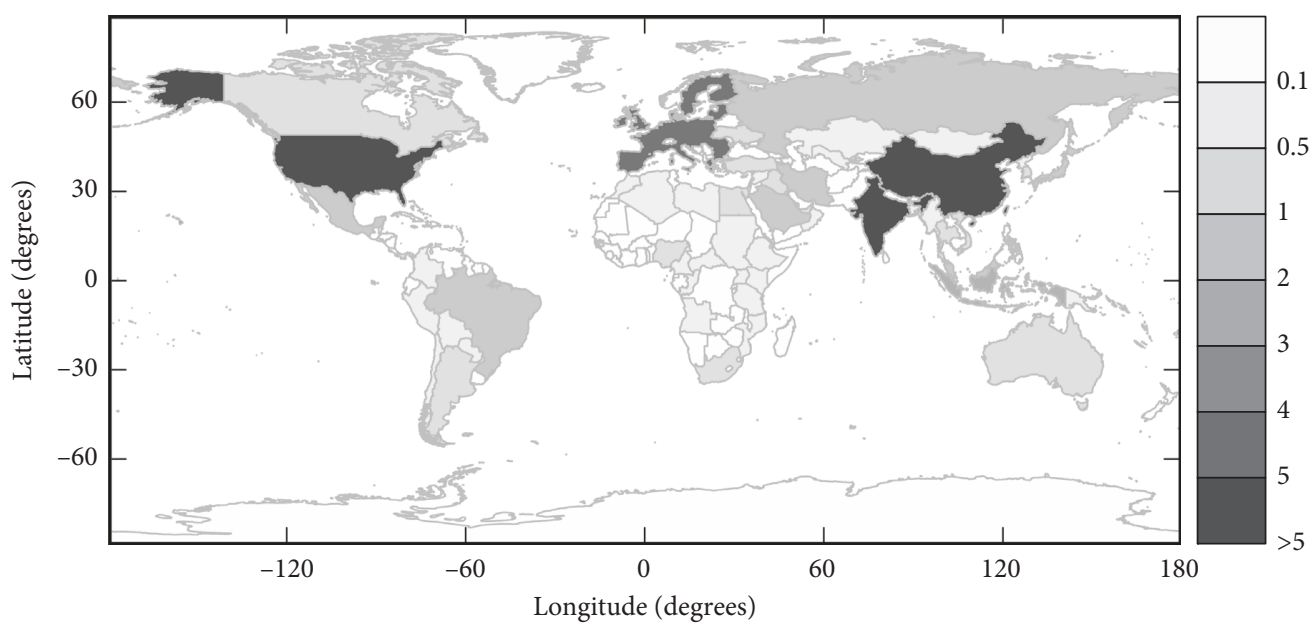

Figure 1: National emissions under Intended Nationally Determined Contribution (INDC) scenarios for unconditional pledges in 2030. The emission target data of each country are calculated based on national INDCs in this study (see Section 2.1 and Supplementary Table S1). Emission level for each country is expressed as a percentage of total global emissions in 2030. The member states of European Union (EU) are shown as a whole as their emission target is submitted for the whole region.

The spatial pattern of global warming under the INDC scenario was estimated based on the time-slice approach [23-26], where the spatial state at a specific warming point related to $\Delta T_{\text {INDC }}$ is taken from the decadal time slices with the respective mean warming for each model separately. This study uses the spatial output from 12 comprehensive Earth system models from the CMIP5 project [27]. These models include BCC_CSM 1.1 (China), CanESM2 (Canada), CESM1 (BGC) (USA), GFDL-ESM2G (USA), GFDL-ESM2M (USA), INM-CM4 (Russia), IPSL-CM5A-LR (France), IPSLCM5A-MR (France), IPSL-CM5B-LR (France), MIROCESM (Japan), and MPI-ESM-LR and MPI-ESM-MR (Germany). We make use of RCP 4.5, 6.0, and 8.5 scenarios and identify the respective warming patterns corresponding to INDC warming for each model, followed by computing a multimodel average state of the spatial warming pattern based on all model simulations. The simulations are regridded into a common $144 \times 72$ grid $\left(2.5^{\circ} \times 2.5^{\circ}\right)$. The CMIP5 models considered in this study are comprehensive Earth system models (ESMs) with coupled carbon-climate system responses, where terrestrial and ocean carbon-cycle processes are coupled with atmosphere-ocean general circulation models $[27,28]$. In addition to CMIP5 ESMs, we also make use of the MAGICC scenario database. The MAGICC model consists of reduced-complexity carbon-cycle and climate models and emulates the global and annual mean behavior of significantly more complex CMIP5 models $[13,14,29]$.

\section{Results}

3.1. INDC Emissions Rate and Cumulative INDC Emissions. Figure 1 shows the emission level of each country in 2030 for unconditional INDC pledges, where emission levels are expressed as a percentage of total global emissions. The countries including China, India, United States, and European Union-28 account for the largest proportions of annual global emissions in 2030 and most underdeveloped countries

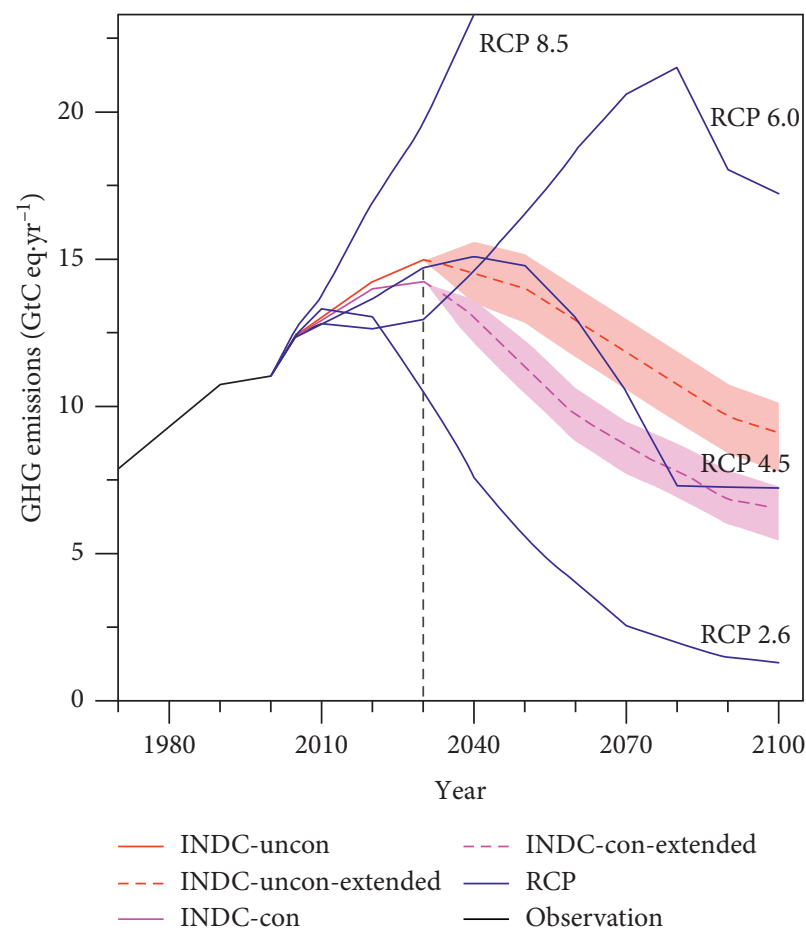

FIGURE 2: Global INDC emissions compared with representative concentration pathway (RCP) scenarios. The black line shows the historical observed emissions. The blue lines show future RCP emission scenarios. Colored lines show Intended Nationally Determined Contribution (INDC) emissions under the unconditional pledge (red line) and conditioned pledge (pink line). Solid (red and pink) lines represent emissions before 2030 and dashed lines represent emissions after 2030.

from Africa, Latin America, and southwest Asia account for a small proportion.

On a global scale, for the unconditional and conditional pledges (Figure 2, red and pink lines), the total INDC 


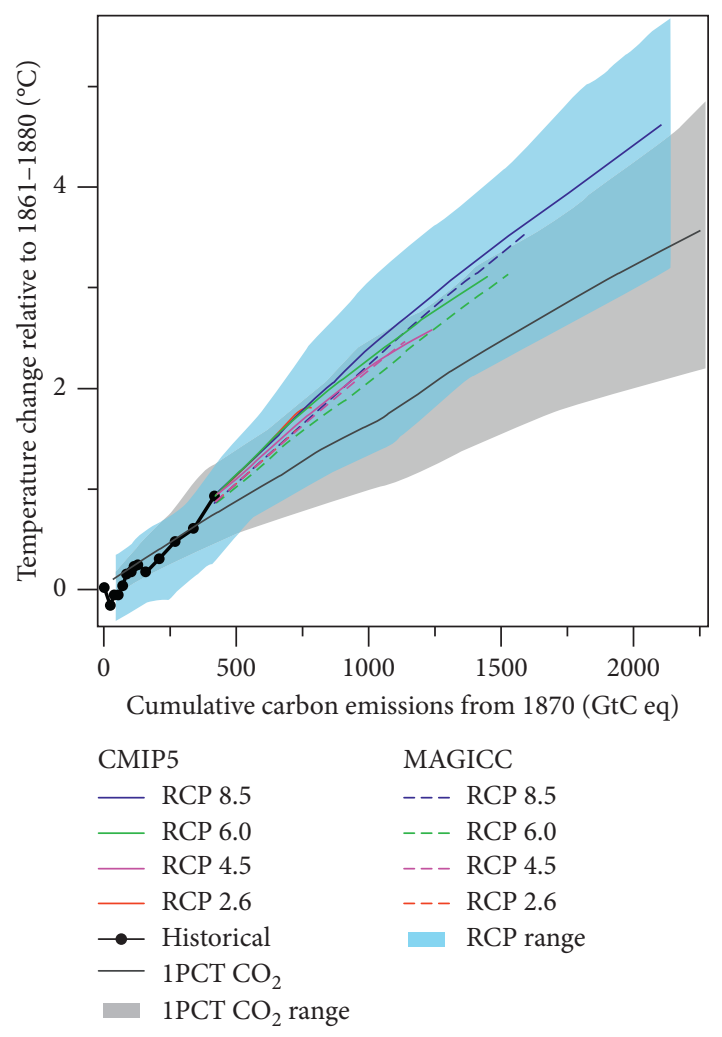

(a)

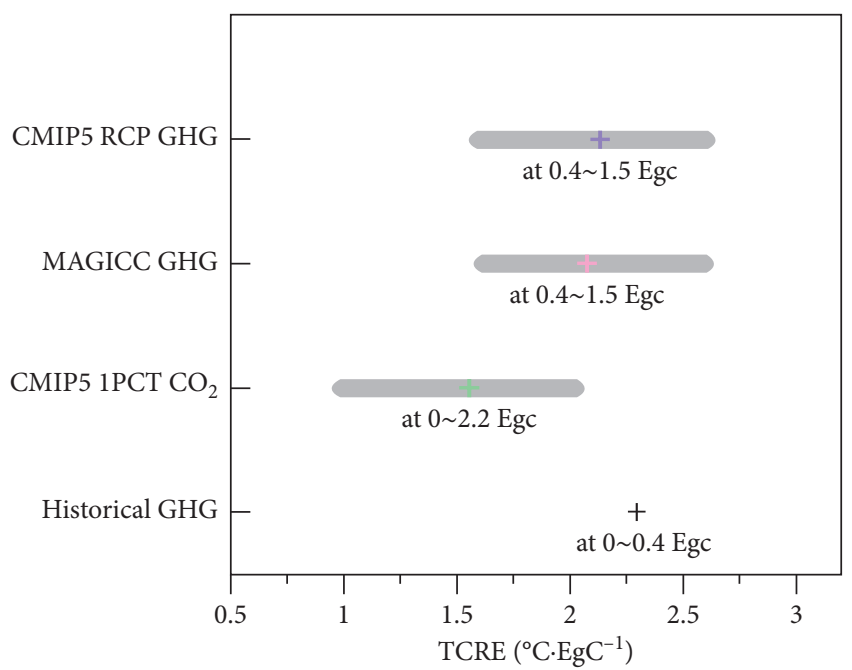

(b)

FIGURE 3: Global temperature change as a function of cumulative carbon emissions from various lines of evidence. (a) Simulated GHG-attributable warming as a function of cumulative emissions based on representative concentration pathway (RCP) and $1 \% \cdot \mathrm{yr}^{-1} \mathrm{CO}_{2}$ increase (1PCT) simulations from the fifth phase of the Coupled Model Intercomparison Project (CMIP5) and Model for the Assessment of Greenhouse Gas Induced Climate Change (MAGICC) experiments. The MAGICC was used in order to compare the results of CMIP5 models used in IPCC Working Group 1 to the MAGICC model results in Working Group 3. (b) The ratio of GHG-attributable warming to cumulative carbon emissions (TCRE). The ranges of numbers in panel (b) indicate the amounts of cumulative emissions from the horizontal axis of (a) for each simulation. These values indicate different ratios of TCRE at different amounts of cumulative emissions from various RCP simulations. emissions target was about 14.2 14.9 GtC/year for 2030, $14.1 \sim 14.6 \mathrm{GtC} /$ year for 2025, and 14.0 14.3 GtC/year for 2020 (Figure 2, solid lines). The rate of annual emission from 2012 to 2030 increased on average by $0.7 \%$ per year. The global INDC emissions target under conditional pledge is about $0.7 \mathrm{GtC} /$ year less than that of the unconditional pledges in 2030. In terms of the RCP emissions, the INDC emissions level was intermediate between the emission levels of RCP 4.5 and RCP 8.5. To extend the INDC emissions to 2100, the continued action of emission reduction was adopted in the scenario over the 21st century. We assumed global emissions peaked in 2030, as this condition is essential for the control of warming to meet long-term targets [30]. In 2050, the estimated GHG emissions were about 11.3 14.0 GtC/year, while in 2100 they were about 6.4 9.0 GtC/year. From 2030 to 2100, the INDC emission level was intermediate between the emission levels of RCP 4.5 and RCP 6.0.

Cumulative emissions for the unconditional and conditional pledges are estimated to be $263 \sim 270 \mathrm{GtC}$ (for the 2012 to 2030 period) and $940 \sim 1120 \mathrm{GtC}$ (for the 2012 to 2100 period). The INDC cumulative emissions during 2012-2100 were higher than those of RCP 2.6 by about $400 \sim 580 \mathrm{GtC}$ but lower than those of RCP 6.0 and RCP 8.5 by about $380 \sim 560 \mathrm{GtC}$ and $1380 \sim 1560 \mathrm{GtC}$, respectively.

3.2. Global Mean Temperature Estimates in Response to INDC Emission Reductions. Global mean temperature is proportional to cumulative carbon emissions for a range of emission scenarios considered here (Figure 3(a)). The black line in Figure 3(a) shows the historical values and the colored lines are the results for different RCP scenarios. It was found that the relationship between cumulative carbon emissions and temperature increase does not differ much for different RCP scenarios for low warming targets (such as $1.5^{\circ} \mathrm{C}$ or $2.0^{\circ} \mathrm{C}$ ) and was nearly constant for each RCP pathway, with only a small and stable change when cumulative emissions approached $2000 \mathrm{GtC}$. The results from MAGICC were well aligned with the CMIP5 results for the RCP pathways. Therefore, for lower temperature targets such as $1.5^{\circ} \mathrm{C}$ and $2.0^{\circ} \mathrm{C}$, this relationship could be used as an approximation of the projection of the climate response to INDC scenarios. We estimated the ratio of a median $\mathrm{TCRE}_{\text {all }}(1)$ of $2.12^{\circ} \mathrm{C}$ per $1000 \mathrm{GtC}$ using CMIP5 results (blue cross in Figure (3b)). The value was about $2.06^{\circ} \mathrm{C}$ per $1000 \mathrm{GtC}$ using MAGICC results (pink cross in Figure 3(b)). The uncertainty range is likely $1.63 \sim 2.59^{\circ} \mathrm{C}$ per $1000 \mathrm{GtC}$ (5 to $95 \%$ ). Note that these values apply to cumulative emissions of up to $600 \mathrm{GtC}$ (about $600 \mathrm{GtC}$ have been emitted at the present time). If only $\mathrm{CO}_{2}$-induced temperature response is considered to estimate climate warming (gray line in Figure 3(a), based on the 1PCT simulations, where atmospheric $\mathrm{CO}_{2}$ concentration increases at a rate of $1 \% \cdot \mathrm{yr}^{-1}$ using CMIP5 models), TCRE is lower, due to lack of the net warming from non$\mathrm{CO} 2$ forcings that are present in the RCP scenarios.

Estimates of global mean warming under INDC emission scenarios are based on the above definition of the climate response to cumulative emissions (TCRE $\mathrm{Tll}_{\text {all }}$ ). For the unconditional INDC pledges (Figure 4(a)), the global mean 

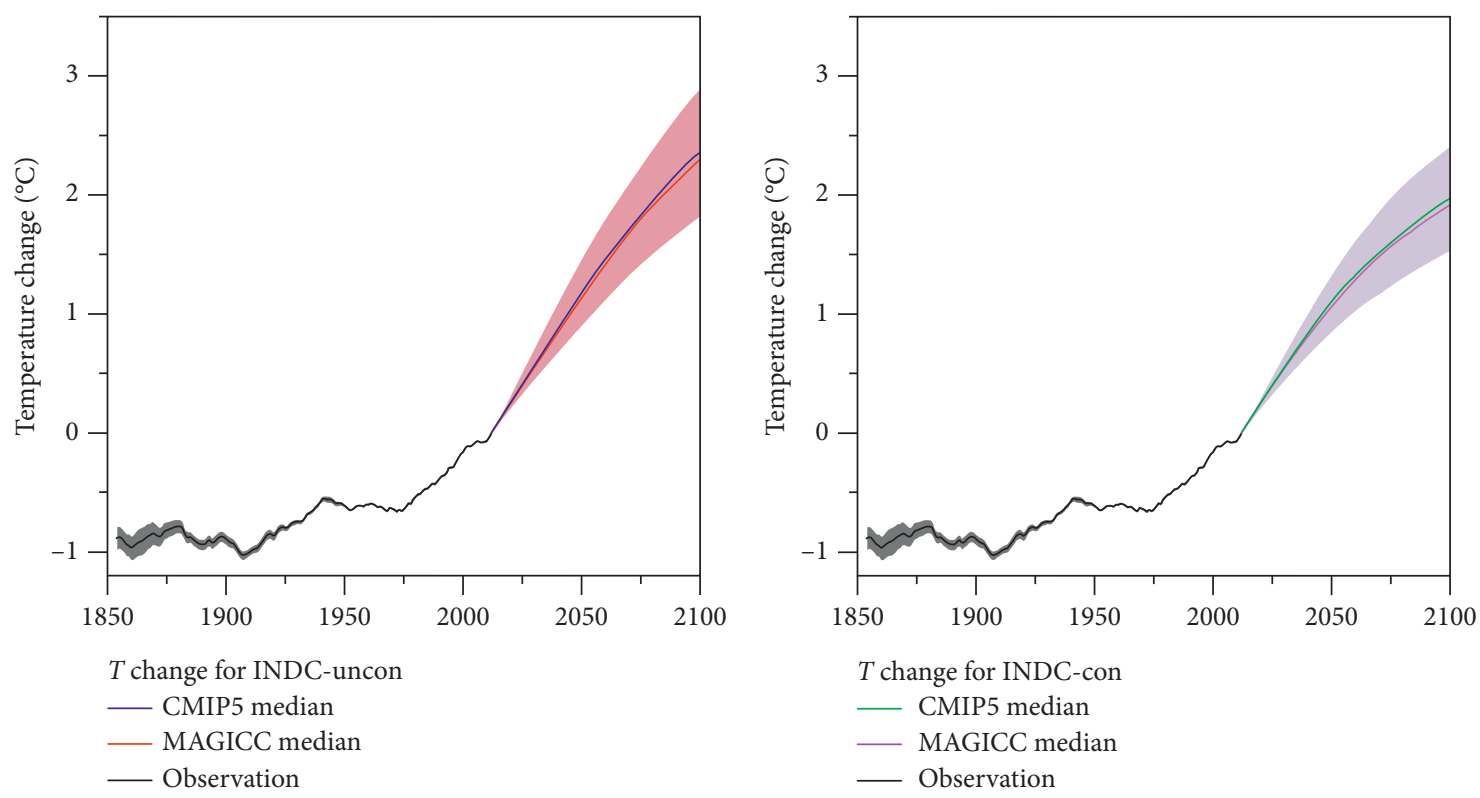

(a)

(b)

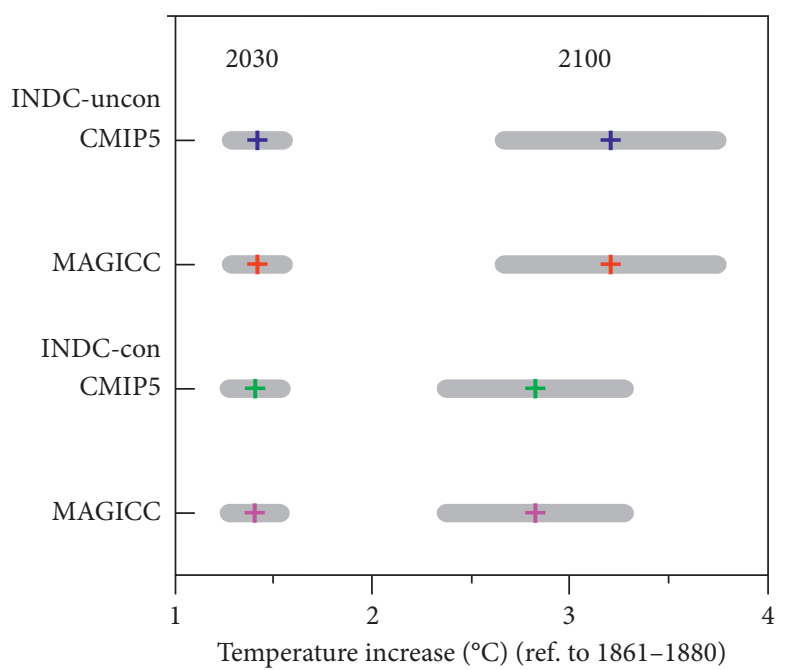

(c)

FIGURE 4: Global temperature increases under Intended Nationally Determined Contribution (INDC) scenarios. (a) unconditional INDC, (b) conditional INDC, and (c) temperature change relative to the preindustrial level (CMIP5: the fifth phase of the Coupled Model Intercomparison Project; MAGICC: Model for the Assessment of Greenhouse Gas Induced Climate Change). The method of calculating temperature response to INDC emissions is presented in Section 2.3. The INDC-induced warming is calculated based on (2) by multiplying $\Delta T_{\text {INDC }}$ (cumulative carbon emission under the INDC scenarios) by TCRE $_{\text {all }}$ (the ratio of GHG-attributable warming to cumulative emissions).

temperature change in 2030 is projected to be $0.57^{\circ} \mathrm{C}$ (median) above the 2012 baseline for the CMIP5 simulations and $0.56^{\circ} \mathrm{C}$ (median) for the MAGICC simulations. The likely range is $0.44 \sim 0.70^{\circ} \mathrm{C}$ (5 to 95\%) above the 2012 baseline. Relative to the preindustrial levels, the increase is projected to be $1.42^{\circ} \mathrm{C}$ and $1.41^{\circ} \mathrm{C}$ for the CMIP5 and MAGICC models, respectively (likely range, $1.29 \sim 1.55^{\circ} \mathrm{C}$ ) (Figure $4(\mathrm{c}))$. By the end of this century, the global temperature is projected to be $2.36^{\circ} \mathrm{C}$ (CMIP5) and $2.30^{\circ} \mathrm{C}$ (MAGICC) (range, $1.82 \sim 2.89^{\circ} \mathrm{C}$ ) above the 2012 baseline and $3.21^{\circ} \mathrm{C}$ (CMIP5) and $3.15^{\circ} \mathrm{C}$ (MAGICC) (range, $2.67 \sim 3.74^{\circ} \mathrm{C}$ ) above the preindustrial level.
Correspondingly, for the conditional INDC pledges (Figure 4(b)), the global temperature increase in 2030 is projected to be $0.56^{\circ} \mathrm{C}$ above the 2012 level for the CMIP5 simulations and $0.54^{\circ} \mathrm{C}$ for the MAGICC simulations (range, $0.43 \sim 0.68^{\circ} \mathrm{C}$ ). In 2100 , the global temperature is projected to be $1.98^{\circ} \mathrm{C}$ (CMIP5) and $1.93^{\circ} \mathrm{C}$ (MAGICC) above the 2012 level (range, $1.53 \sim 2.42^{\circ} \mathrm{C}$ ) and $2.83^{\circ} \mathrm{C}$ (CMIP5) and $2.78^{\circ} \mathrm{C}$ (MAGICC) above the preindustrial level (Figure 4(c)).

Figures 5(a) and 5(b) show multimodel mean regional patterns of surface temperature changes for unconditional INDC scenario in 2030 and 2100, respectively. The Arctic 


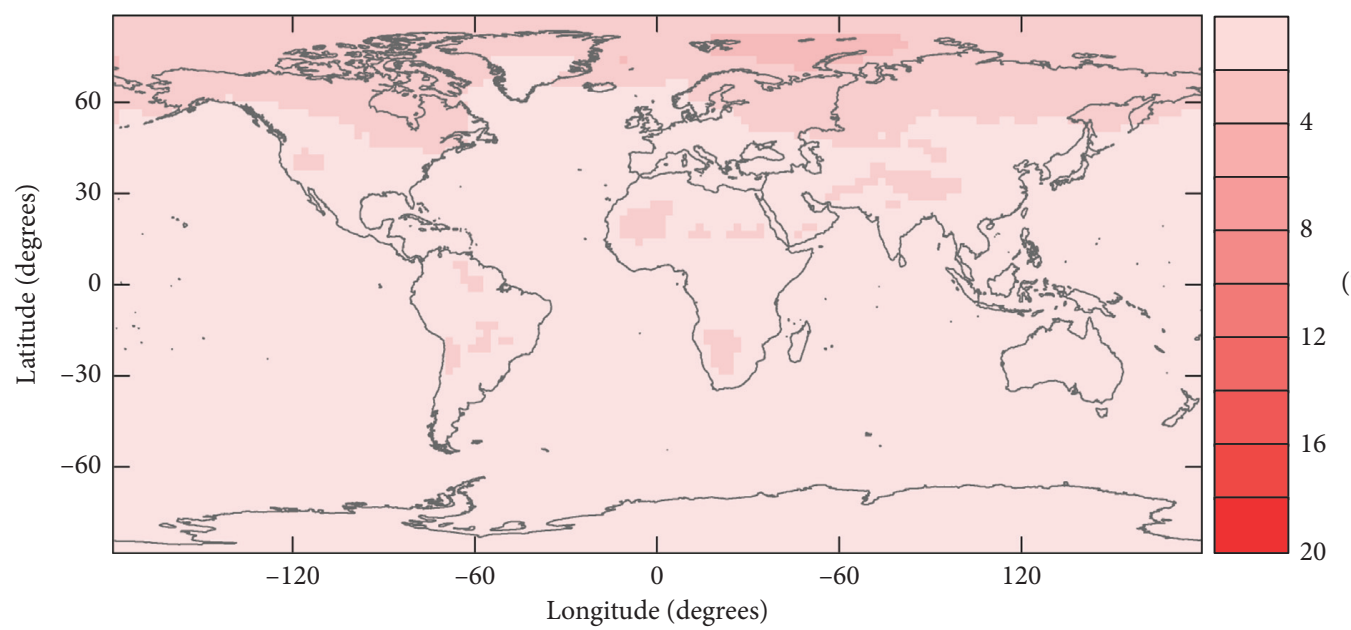

$\left({ }^{\circ} \mathrm{C}\right)$

(a)

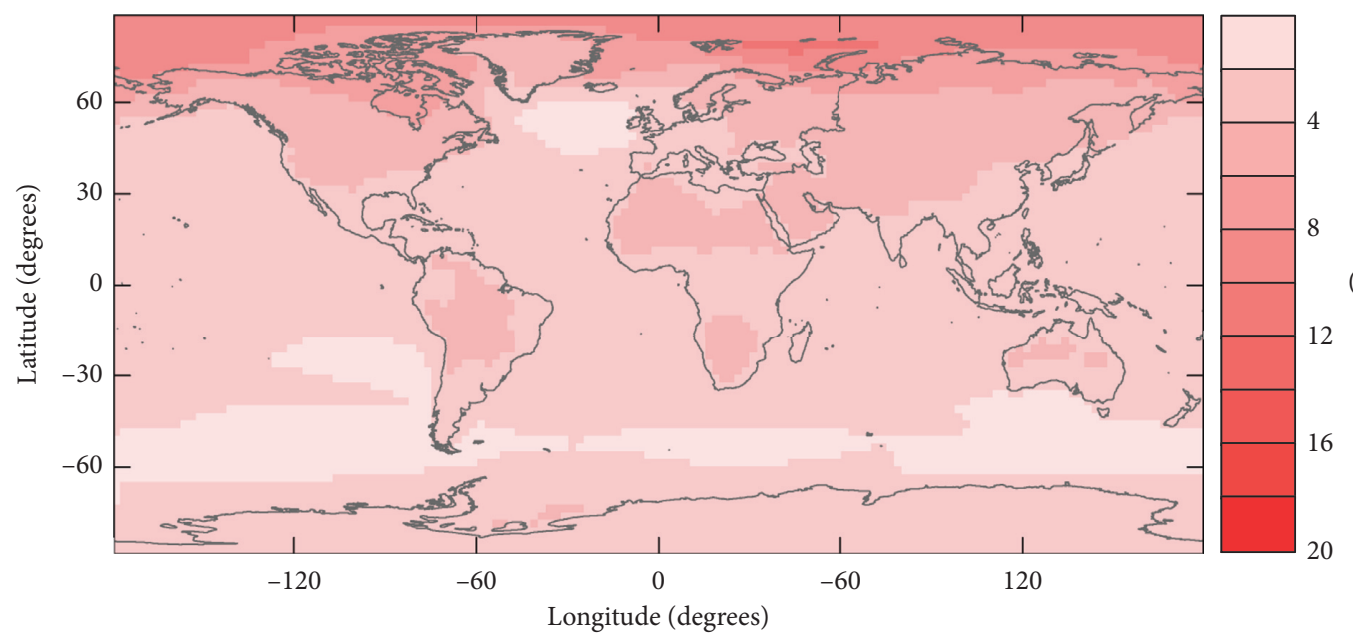

$\left({ }^{\circ} \mathrm{C}\right)$

(b)

Figure 5: Simulated model mean temperature changes in response to Intended Nationally Determined Contribution (INDC) emissions for unconditional pledges in (a) 2030 and (b) 2100. The temperature anomalies are relative to preindustrial levels. The simulation data from 12 CMIP5 models were used to produce an average state of warming pattern for INDC (see Section 2.3). The 2030 spatial pattern for INDC was estimated based on RCP 4.5 scenario experiment due to the similar emission levels of RCP 4.5 and INDC for 2030 . The 2100 spatial pattern for INDC was estimated based on RCP 6.0 and 8.5 scenarios experiments due to the available simulations of the two scenarios for larger temperature increases.

warming is projected to be most profound, exceeding the global average by a factor of three, with about $3 \sim 5^{\circ} \mathrm{C}$ Arctic warming in 2030 and $8 \sim 10^{\circ} \mathrm{C}$ in 2100 relative to the preindustrial level. The warming in midlatitude is nearly a factor of two greater than the global average in both 2030 and 2100. The south oceans and parts of North Atlantic exhibit lowest warming (Figures 5(a) and 5(b)).

\section{Discussion and Conclusions}

Our study estimated the global mean temperature increase under the INDC commitments in 2030 to range from 1.29 to $1.55^{\circ} \mathrm{C}$ (median of $1.41^{\circ} \mathrm{C}$ ) above the preindustrial level, reaching $2.67 \sim 3.74^{\circ} \mathrm{C}$ (median of $3.17^{\circ} \mathrm{C}$ ) in 2100 . Our best estimates were within the reported ranges from other studies (e.g., UNEP [31], CI [32], and CAT [33]). Our best estimate for global mean warming is a little higher than that of Rogelj et al.[30] (the median of $2.6 \sim 3.1^{\circ} \mathrm{C}$ ). We also compared the results of this study with the temperature increase resulting from the RCP scenarios, reported in IPCC AR5 [16, 34]. Table 1 gives the warming estimates for each scenario in 2030 and 2100. In 2030, the INDC level of warming will be higher than that estimated from RCP 2.6 and 6.0, but lower than that estimated in RCP 8.5. However, the temperature differences between the INDC scenarios and other scenarios are very small (in the order of $0.01^{\circ} \mathrm{C}$ ). In 2100 , the INDC warming will be higher than that estimated form RCP 4.5 and 2.6 scenarios and lower than that estimated from RCP 6.0 and 8.5 , but closer to the warming estimated in RCP 4.5 and RCP 6.0 (Table 1). Sanderson et al. [35] proposed a set of idealized emission pathways consistent with reaching the $2^{\circ} \mathrm{C}$ temperature target, which showed that if the INDCs for 2030 remain the same as committed, only net zero GHG emissions by 2085 and negative emissions implemented later 
TABle 1: Temperature projections for Intended Nationally Determined Contribution (INDC) and representative concentration pathway (RCP) scenarios (relative to preindustrial levels).

\begin{tabular}{lccc}
\hline \multirow{2}{*}{ Scenario } & & \multicolumn{2}{c}{$\begin{array}{c}\text { Temperature increase } \\
\left({ }^{\circ} \mathrm{C}\right)\end{array}$} \\
& & $2030^{1}$ & $2100^{2}$ \\
\hline \multirow{2}{*}{ INDC } & Unconditional & 1.41 & 3.17 \\
& & $(1.29 \sim 1.55)$ & $(2.67 \sim 3.74)$ \\
& Conditional & 1.39 & 2.80 \\
& & $(1.28 \sim 1.53)$ & $(2.38 \sim 3.27)$ \\
\hline \multirow{2}{*}{ RCP 2.6 } & 430-480 ppm $\left(\mathrm{CO}_{2}\right.$ eq. & $\sim 1.3$ & $1.5-1.7$ \\
RCP 4.5 & concentration in 2100) & & \\
& $580-650 \mathrm{ppm}$ & & $2.3-2.6$ \\
RCP 6.0 & 650-720 ppm & $\sim 1.3$ & $2.6-2.9$ \\
RCP 8.5 & $720-1000 \mathrm{ppm}$ & $\sim 1.5$ & $4.1-3.7$ \\
\hline
\end{tabular}

"1" represents the best estimate (median). “ " refers to the approximate estimate based on RCP scenario data from the Fifth Assessment Report (AR5) of the Intergovernmental Panel on Climate Change (IPCC). "2" refers to RCP data directly from Table 6.3 in the IPCC Workgroup 3 report.

in the century are required to limit the global mean warming below the $2^{\circ} \mathrm{C}$ warming. However, such rapid emission reductions would be quite difficult to implement [30].

Compared with the long-term temperature-limiting targets, the global mean warming resulting from INDC emission reductions exceeds the $2^{\circ} \mathrm{C}$ or $1.5^{\circ} \mathrm{C}$ stabilization goals set by UNFCCC [36]. Therefore, even the conditional INDCs and resulting emission reductions are insufficient to meet the globally agreed long-term goal of limiting global mean warming to well below $2^{\circ} \mathrm{C}$ or $1.5^{\circ} \mathrm{C}$. To achieve the desired temperature levels in the future, it is therefore necessary to adjust and strengthen the INDC emissionreduction commitments.

Regional climate change prediction is more relevant for assessing impact-related temperature-controlled goals. The results indicate that by 2030 the high-latitude regions show higher warming level under INDC emission pledges, while by 2100 the significant warming trends will reach across the globe. In particular, the intense warming of the Arctic and other high-latitude land regions may have serious implications for other components of the Earth system (e.g., Arctic summer sea ice retreat, Alpine glaciers loss, and coral reefs bleaching). Future regional extreme climate change should be given more attention.

The results presented in this study are sensitive to future non- $\mathrm{CO}_{2}$ emission trajectories, which are not fully included in the INDC-committed emission reductions. For example, strong aerosol emissions could have negative effects on warming, even by several tenths of a degree in the short term $[37,38]$. Further research is needed regarding the probability distribution of warming in response to INDC scenarios and its sensitivity to different non- $\mathrm{CO}_{2}$ emission trajectories.

The global mean temperature under different INDC emission scenarios was estimated using estimates of TCRE based on CMIP5 and MAGICC responses. The advantage of this approach is the avoidance of high costs of running all comprehensive ESMs to simulate the climate response under INDC scenarios. This approach also incorporates the overall structural uncertainty from ranges of model responses from model ensembles, rather than the results based only on one model. Note that the MAGICC TCRE all values are slightly lower than that of CMIP5 mean value (as shown in Figures 3 (a) and 3(b)). This is why the estimated future climate from IPCC WG1 is slightly warmer than that from the IPCC WG3. The results presented here are also subject to uncertainties due to different representation of carbon cycle processes in climate models. Also, since permafrost carbon cycle feedbacks and ice sheets are not currently represented in CMIP5 models considered here, they could lead to even higher warming levels and associated feedbacks.

INDC emission pledges are nonbinding and will be evaluated every five years, with the pre-evaluation by UNFCCC in 2018, and the first formal evaluation in 2023. The outcome will be used as the input for new INDCs. Therefore, it is necessary to evaluate the climate impacts of the new INDCs in a timely manner. Our study shows that climate warming under current INDC scenarios is projected to greatly exceed the long-term Paris Agreement goal of stabilizing the global mean temperature at $2^{\circ} \mathrm{C}$ or $1.5^{\circ} \mathrm{C}$ above the preindustrial level, suggesting that rapid emission reductions in conjunction with negative emissions [30] may be necessary to ensure temperature stabilization consistent with the Paris Agreement.

\section{Data Availability}

The data that support the findings of this study are available from the corresponding author upon request. CMIP5 model data are publically available at the Earth System Grid Server at http://pcmdi9.llnl.gov/.

\section{Conflicts of Interest}

The authors declare that they have no competing interests.

\section{Acknowledgments}

This work was supported by the National Key Research and Development Program of China (2016YFA0602704), the National Natural Science Foundation of China (41771050), the CAS Key Project (No. KJZD-EW-TZG10) and the Reform and Development Research Program of Ministry of Science and Technology "Imperative and significant problems to addressing climate change after Paris Conference".

\section{Supplementary Materials}

The INDC reports include 192 countries that submitted their pledges through 2017, in which the 28 member states of EU submitted an INDC target as a whole for the region. We analyzed and calculated these countries' mitigation objectives and the details can be found in Supplementary Table S1. The INDC emission targets consist of both the unconditional targets and conditional targets. (Supplementary Materials) 


\section{References}

[1] UNFCCC, Adoption of the Paris Agreement: Proposal by the President, Tech. Rep. FCCC/CP/2015/L.9/Rev.1, UNFCCC, Geneva, Switzerland, 2015.

[2] UNFCCC, INDCs as Communicated by Parties, 2016, http:// www4.unfccc.int/submissions/indc/Submission\%20Pages/ submissions.aspx.

[3] M. R. Allen, D. J. Frame, C. Huntingford et al., "Warming caused by cumulative carbon emissions towards the trillionth tonne," Nature, vol. 458, no. 7242, pp. 1163-1166, 2009.

[4] N. P. Gillett, V. K. Arora, D. Matthews, and M. R. Allen, "Constraining the ratio of global warming to cumulative $\mathrm{CO}_{2}$ emissions using CMIP5 simulations," Journal of Climate, vol. 26, no. 18, pp. 6844-6858, 2013.

[5] T. C. Johns, J.-F. Royer, I. Höschel et al., "Climate change under aggressive mitigation: the ENSEMBLES multi-model experiment," Climate Dynamics, vol. 37, no. 9-10, pp. 19752003, 2011.

[6] H. D. Matthews, N. P. Gillett, P. A. Stott, and K. Zickfeld, "The proportionality of global warming to cumulative carbon emissions," Nature, vol. 459, no. 7248, pp. 829-832, 2009.

[7] J. Rogelj, M. Meinshausen, and R. Knutti, "Global warming under old and new scenarios using IPCC climate sensitivity range estimates," Nature Climate Change, vol. 2, no. 4, pp. 248-253, 2012.

[8] K. B. Tokarska, N. P. Gillett, A. J. Weaver, V. K. Arora, and M. Eby, "The climate response to five trillion tonnes of carbon," Nature Climate Change, vol. 6, no. 9, pp. 851-856, 2016.

[9] K. Zickfeld, M. Eby, H. D. Matthews, and A. J. Weaver, "Setting cumulative emissions targets to reduce the risk of dangerous climate change," Proceedings of the National Academy of Sciences of the United States of America, vol. 106, no. 38, pp. 16129-16134, 2009.

[10] K. Zickfeld, M. Eby, A. J. Weaver et al., "Long-term climate change commitment and reversibility: an EMIC intercomparison," Journal of Climate, vol. 26, no. 16, pp. 5782-5809, 2013.

[11] R. H. Moss, J. A. Edmonds, K. A. Hibbard et al., "The next generation of scenarios for climate change research and assessment," Nature, vol. 463, no. 7282, pp. 747-756, 2010.

[12] K. E. Taylor, R. J. Stouffer, and G. A. Meehl, "An overview of CMIP5 and the experiment design," Bulletin of the American Meteorological Society, vol. 93, no. 4, pp. 485-498, 2012.

[13] M. Meinshausen, S. C. B. Raper, and T. M. L. Wigley, "Emulating coupled atmosphere-ocean and carbon cycle models with a simpler model, MAGICC6-part 1: model description and calibration," Atmospheric Chemistry and Physics, vol. 11, no. 4, pp. 1417-1456, 2011.

[14] M. Meinshausen, T. M. L. Wigley, and S. C. B. Raper, "Emulating atmosphere-ocean and carbon cycle models with a simpler model, MAGICC6-part 2: applications," Atmospheric Chemistry and Physics, vol. 11, no. 4, pp. 1457-1471, 2011.

[15] K. Caldeira and J. F. Kasting, "Insensitivity of global warming potentials to carbon dioxide emission scenarios," Nature, vol. 366, no. 6452, pp. 251-253, 1993.

[16] M. Collins, R. Knutti, J. Arblaster et al., "Long-term climate change: projections, commitments and irreversibility," in Climate Change 2013: the Physical Science Basis. Contribution of Working Group I to the Fifth Assessment Report of the Intergovernmental Panel on Climate Change, T. F. Stocker, D. Qin, G.-K. Plattner et al., Eds., pp. 1029-1136, Cambridge University Press, Cambridge, UK, 2013.

[17] T. Hajima, T. Ise, K. Tachiiri, E. Kato, S. Watanabe, and M. Kawamiya, "Climate change, allowable emission, and earth system response to representative concentration pathway scenarios," Journal of the Meteorological Society of Japan. Ser. II, vol. 90, no. 3, pp. 417-434, 2012.

[18] M. C. Sarofim, C. E. Forest, D. M. Reiner, and J. M. Reilly, "Stabilization and global climate policy," Global and Planetary Change, vol. 47, no. 2, pp. 266-272, 2005.

[19] UNFCCC, National Inventory Submissions, 2018, http:// unfccc.int/national_reports/annex_i_ghg_inventories/national_ inventories_submissions/items/10566.php.

[20] T. Athanasiou, S. Kartha, and P. Baer, National Fair Shares: The Mitigation Gap-Domestic Actions \& International Support, 2016, https://climateequityreference.org/nationalfair-shares-the-mitigation-gap-domestic-actions-internationalsupport/.

[21] G. Myhre, D. Shindell, F.-M. Bréon et al., "Anthropogenic and natural radiative forcing," in Climate Change 2013: the Physical Science Basis. Contribution of Working Group I to the Fifth Assessment Report of the Intergovernmental Panel on Climate Change, T. F. Stocker, D. Qin, G.-K. Plattner et al., Eds., pp. 659-740, Cambridge University Press, Cambridge, UK, 2013.

[22] D. L. Hartmann, A. M. G. Klein Tank, M. Rusticucci et al., "Observations: atmosphere and surface," in Climate Change 2013: the Physical Science Basis. Contribution of Working Group I to the Fifth Assessment Report of the Intergovernmental Panel on Climate Change, T. F. Stocker, D. Qin, G.-K. Plattner et al., Eds., pp. 159-254, Cambridge University Press, Cambridge, UK, 2013.

[23] C. Giannakopoulos, P. Le Sager, M. Bindi, M. Moriondo, E. Kostopoulou, and C. M. Goodess, "Climatic changes and associated impacts in the Mediterranean resulting from a 2 degrees C global warming," Global and Planetary Change, vol. 68 , no. 3, pp. 209-224, 2009.

[24] R. Vautard, A. Gobiet, S. Sobolowski et al., "The European climate under a 2 degrees C global warming," Environmental Research Letters, vol. 9, no. 3, p. 034006, 2014.

[25] C. R. Schleussner, T. K. Lissner, E. M. Fischer et al., "Differential climate impacts for policy-relevant limits to global warming: the case of $1.5^{\circ} \mathrm{C}$ and $2^{\circ} \mathrm{C}$," Earth System Dynamics, vol. 7, no. 2, pp. 327-351, 2016.

[26] J. P. Huang, H. P. Yu, A. G. Dai, Y. Wei, and L. T. Kang, "Drylands face potential threat under 2 degrees $\mathrm{C}$ global warming target," Nature Climate Change, vol. 7, no. 6, pp. 417-422, 2017.

[27] V. K. Arora, G. J. Boer, P. Friedlingstein et al., "Carbonconcentration and carbon-climate feedbacks in CMIP5 earth system models," Journal of Climate, vol. 26, no. 15, pp. 5289-5314, 2013.

[28] World Climate Research Programme (WCRP), "WCRP coupled model intercomparison project phase 5-CMIP5," CLIVAR Exchanges (Special Issue), pp. 1-52, 2011.

[29] V. Krey, O. Masera, G. Blanford et al., “Annex II: metrics \& methodology," in Climate Change 2014: Mitigation of Climate Change. Contribution of Working Group III to the Fifth Assessment Report of the Intergovernmental Panel on Climate Change, O. Edenhofer, R. Pichs-Madruga, Y. Sokona et al., Eds., Cambridge University Press, Cambridge, UK, 2014.

[30] J. Rogelj, M. den Elzen, N. Höhne et al., "Paris agreement climate proposals need a boost to keep warming well below 2 ${ }^{\circ}$," Nature, vol. 534, no. 7609, pp. 631-639, 2016.

[31] United Nations Environment Program (UNEP), The Emissions Gap Report 2015, UNEP, Nairobi, Kenya, 2016. 
[32] Climate Interactive (CI), Climate Scoreboard, UN Climate Pledge Analysis, 2016, https:/www.climateinteractive.org/ programs/scoreboard/.

[33] Climate Action Tracker (CAT), Climate Pledges Will Bring $2.7^{\circ} \mathrm{C}$ of Warming, Potential for More Action, 2015, http:// www.climateactiontracker.org/news/253/Climate-pledges-willbring-2.7C-of-warming-potential-for-more-action.html.

[34] L. Clarke, K. Jiang, K. Akimoto et al., "Assessing transformation pathways," in Climate Change 2014: Mitigation of Climate Change. Contribution of Working Group III to the Fifth Assessment Report of the Intergovernmental Panel on Climate Change, O. Edenhofer, R. Pichs-Madruga, Y. Sokona et al., Eds., Cambridge University Press, Cambridge, UK, 2014.

[35] B. M. Sanderson, B. C. O’Neill, and C. Tebaldi, "What would it take to achieve the Paris temperature targets?," Geophysical Research Letters, vol. 43, no. 13, pp. 7133-7142, 2016.

[36] UNFCCC, "Synthesis report on the aggregate effect of the intended nationally determined contributions," Tech. Rep. FCCC/CP/2015/7, UNFCCC, Paris, France, 2015.

[37] D. Shindell, J. C. I. Kuylenstierna, E. Vignati et al., "Simultaneously mitigating near-term climate change and improving human health and food security," Science, vol. 335, no. 6065 , pp. 183-189, 2012.

[38] K. Tanaka and T. Raddatz, "Correlation between climate sensitivity and aerosol forcing and its implication for the "climate trap"," Climatic Change, vol. 109, no. 3, pp. 815-825, 2011. 

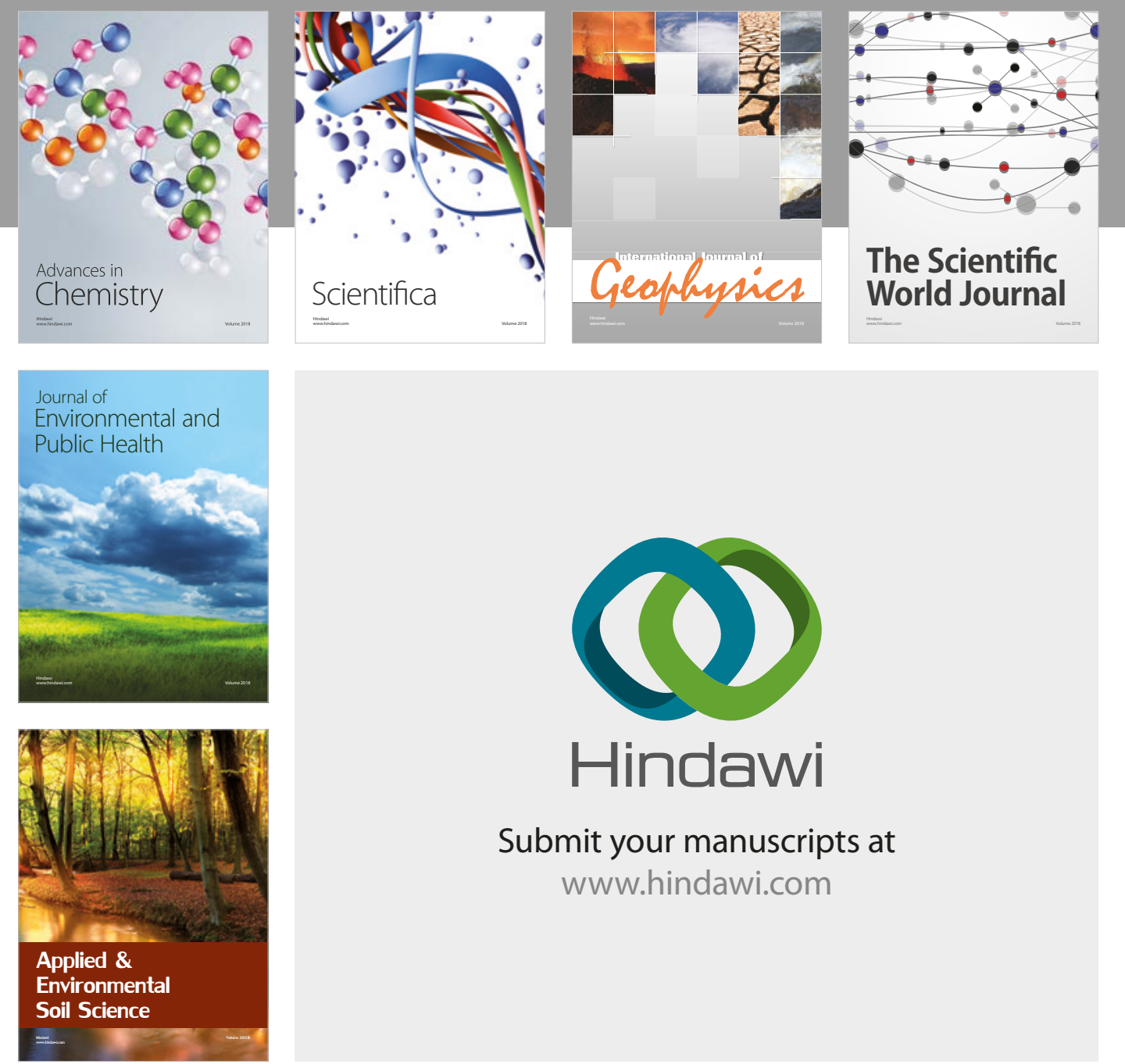

The Scientific

\section{World Journal}
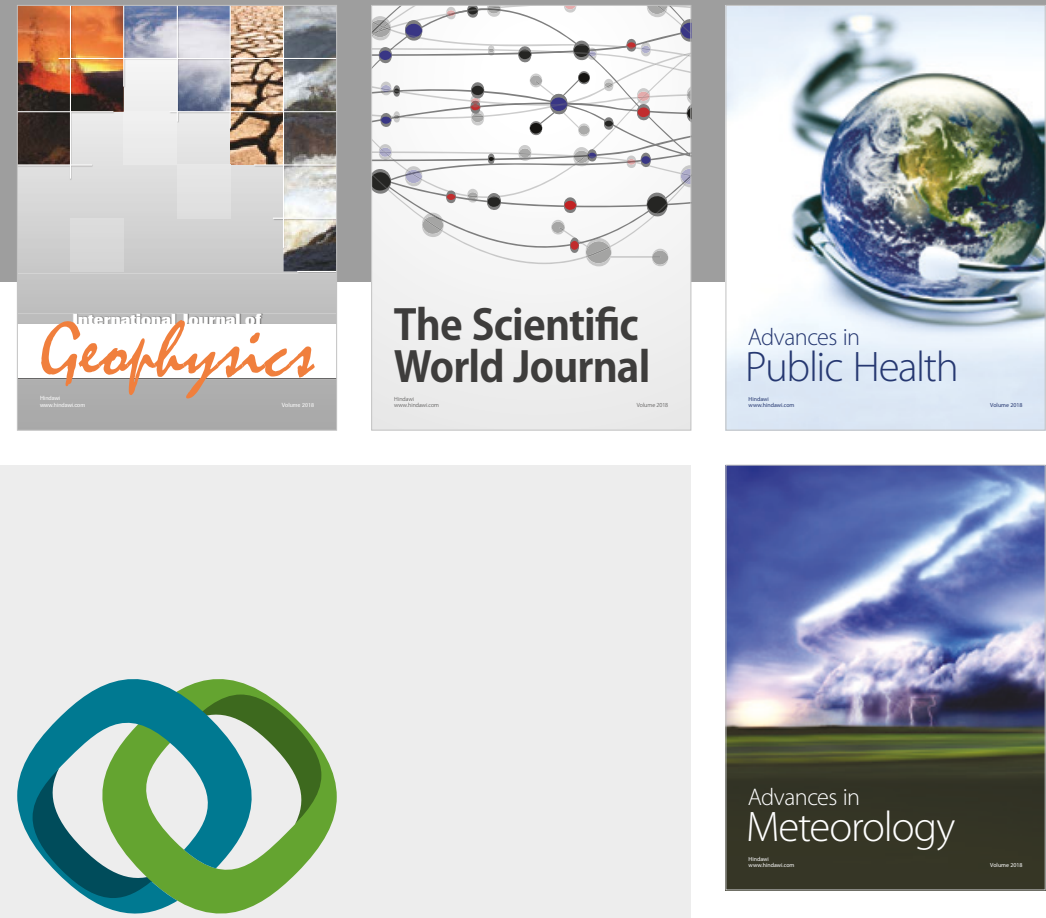

Advan

Public Health

\section{Hindawi}

Submit your manuscripts at

www.hindawi.com
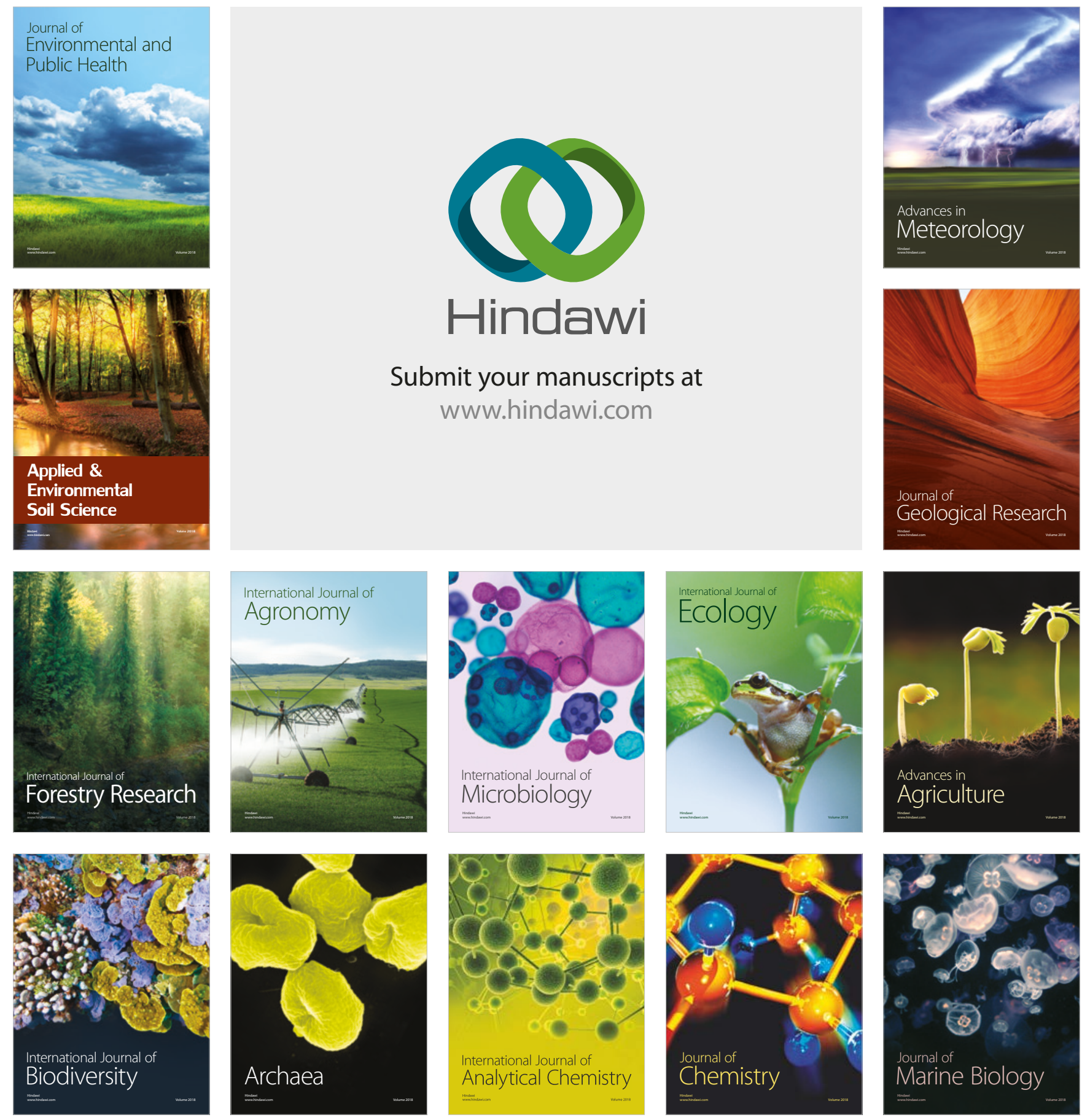